\title{
Effects of Dietary Supplementation of Fumaric Acid on Growth Performance, Blood Hematological and Biochemical Profile of Broiler Chickens Exposed to Chronic Heat Stress
}

\section{-Author(s)}

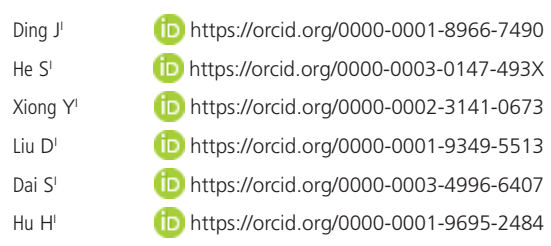

College of Animal Science, Anhui Science and Technology University, Fengyang, China.

\section{-Mail Address}

Corresponding author e-mail address He Shaojun

College of Animal Science,

Anhui Science \& Technology University,

No.9, Donghua Road, Fengyang County

Chuzhou City, Anhui Province, 233100

China.

Phone: +0086-15855035823

Email: shaojunhe2011@126.com

\section{aKeywords}

Fumaric acid; broiler; chronic heat stress; heamatology; biochemistry.

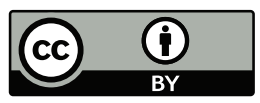

Submitted: 25/July/2019

Approved: 10/December/2019

\section{ABSTRACT}

The aim of this study was to investigate the effects of dietary fumaric acid (FA) on the growth performance, hematological parameters and serum biochemistry in broilers under heat stress (HS) condition. A total number of 200 broilers were allocated to five treatments including the thermoneutral group, which was reared at standard ambient temperature and fed basal diet (CONT) and four heat-stressed groups, which were held at $32 \pm 1^{\circ} \mathrm{C}$ aged from 22 to 42 days and fed the basal diet supplemented with $0,5,10$ and $15 \mathrm{~g} / \mathrm{kg}$ FA, respectively. On day 42, body weight and feed intake were measured and feed conversion ratio was calculated. Blood was collected for the estimation of hematological and biochemical parameters. HS impaired the growth performance, but the addition of FA made a higher final body weight, average daily gain and European broiler index in comparison with HS group. The hemoglobin concentration and packed cell volume of HS broilers were significantly lower than those of the CONT birds. Birds administered $5 \mathrm{~g} / \mathrm{kg}$ FA diet had significantly $(p<0.05)$ higher erythrocyte counts and hemoglobin concentration compared with birds in the HS group fed basal diet. Also, the HS group exhibited significant increase in glucose, triglyceride, total cholesterol, low-density lipoprotein cholesterol and creatinine when compared with CONT group. Dietary $5 \mathrm{~g} / \mathrm{kg}$ FA increased the serum total protein, albumin, globulin, total cholesterol, high-density lipoprotein cholesterol in comparison with the HS group. In conclusion, this study demonstrated the importance of using FA as feed additives to improve the growth performance of heatstressed broilers through haematological and biochemical regulation.

\section{INTRODUCTION}

High ambient temperature is a substantial unfavorable environmental factor for successful poultry production in tropical, subtropical and temperate regions of the world which constitutes serious production efficiency concerns (Lara, 2013). As a most significant abiotic factor, it can significantly influence the metabolism of chickens. Heat-induced physiological changes are greatly affected by duration of heat exposure. The acute heat stress (HS) lasting for hours to a few days is regulated by homeostatic regulators of the nervous and endocrine systems and the chronic HS lasting several days to weeks by homeorhetic regulators of the endocrine system (Collier et al., 2017). He et al. (2018) reported that continuous exposure to high ambient temperature overwhelms the homeostatic mechanisms in poultry, which may consequently compromise their growth performance, immunity, meat quality, and so on. High temperature significantly affects the physiology of broiler chicken and the central nervous system (CNS) via the hypothalamus and modulates most of the hematological and biochemical changes (Habibu et al., 2018). Specifically, the CNS modulates hematology 
parameters and serum biochemistry by influencing respiration, circulation, sweating and water intake to enhance heat loss during HS. Consequently, hematological and biochemical variations in the blood are intrinsically related to climate factors and they are essential indicators of physiological changes in a variety of animals. It is urgent to reduce the heat strain by adjusting broiler physiology and metabolism and enhances the productivity of broiler chickens reared at high ambient temperature.

A prevalent method in poultry production is to take advantage of the use of specific dietary supplements to achieve better poultry performance and feed conversion. Organic acids are generally considered as safe and have been approved by most member states of the European Union to be used as the feed additives in animal production (Habibu et al., 2018). Organic acids feeding is believed to have several beneficial effects such as improving feed conversion ratio $(F C R)$, growth performance, enhancing mineral absorption, and speeding recovery from fatigue (Adil 2015; Kim et al., 2015). Fumaric acid (FA) is a dicarboxylic acid, naturally present in all organisms. Exogenous FA will be rapidly metabolized and it is not expected to accumulate in animal tissues and products (EFSA Panel 2016). FA predominantly takes part in the tricarboxylic acid cycle and dietary FA addition may change apparent metabolizable energy (Durek et al., 2014). Waldroup et al. (1995) reported that dietary fumaric supplementation to broilers results in improved weight gain and feed conversion under thermoneutral condition. Blood is probably the most potent medium in the body that facilitates heat dissipation during HS via its role insensible and insensible heat loss through the skin and respiratory tract (Singh et al., 2016). Hence, blood hematological and serum biochemical analyses have been necessary for detecting changes in the health status of birds. However, there is a lack of information on the effects of FA on the hematological and biochemical responses of broiler chickens reared under the thermally stressful condition. Therefore, the present study aimed to evaluate the growth performance, hematological and serum biochemical responses of heat-stressed broiler chickens when treated with dietary FA.

\section{MATERIALS AND METHODS}

\section{Experimental Birds, Management and FA Treatment}

The animal protocol was approved by the Animal Care and Use Committee of Anhui Science and
Technological University. A total of 200 Ross 308 broiler chickens with similar initial body weight were randomly allocated to five groups with four replicates of ten broilers per replicate from 22 to 42 days of age. Every replicate broilers were reared in one cage $(90 \mathrm{~cm}$ length $\times 90 \mathrm{~cm}$ width $\times 38 \mathrm{~cm}$ height) with the relative humidity of $(60 \pm 5) \%$. The broilers in the control group were raised at $23 \pm 1$ ${ }^{\circ} \mathrm{C}$ in a temperature-controlled room and received a basal diet (Table 1). The broilers in the HS group were raised at $32 \pm 1{ }^{\circ} \mathrm{C}$ and were fed the same basal diet supplemented with $0,5,10$ and $15 \mathrm{~g} / \mathrm{kg}$ FA in another temperature-controlled room, respectively. Each room was equipped with thermostatically controlled electric heaters and an electric fan for the circulation of air. Broilers were allowed free access to feed and water and were maintained on a 23L:1D lighting program. They were also vaccinated against Newcastle disease (on day 21) using the Lasota vaccine. At the end of the experiment, feed intake during the trial was calculated and the broilers were weighed after feed deprivation for $12 \mathrm{~h}$ by replicate to calculate average daily gain and FCR. The mortality rate of chicks was recorded in all the treatments at the end of the studied period. The European Broiler Index (EBI) was also calculated using the following equation (Islam et al., 2012).

European Broiler Index $(\mathrm{EBI})=$ (average daily gain $\times$ per cent survival)/(10xfeed conversion)

\section{Blood Routine Test}

At the end of the experiment, blood samples (approximately $5 \mathrm{~mL}$ ) from 8 birds in each group ( 2 birds per replicate) were collected aseptically from the wing vein with vacutainer tubes, which contained anticoagulant disodium ethylene diamine tetraacetic acid. After collection, the blood samples were immediately transferred to the laboratory for analysis. The blood samples were analyzed automatically (Mindray, BC-2800vet, China) including total erythrocyte count $\left(\mathrm{RBC}, \times 10^{12} / \mathrm{L}\right)$, hemoglobin concentration ( $\mathrm{Hb}, \mathrm{g} / \mathrm{L})$, packed cell volume (PCV, \%), mean corpuscular volume (MCV, fL), mean corpuscular hemoglobin $(\mathrm{MCH}, \mathrm{pg})$, mean corpuscular hemoglobin concentration (MCHC, g/L), total leucocyte count $\left(\right.$ WBC, $\left.\times 10^{8} / \mathrm{L}\right)$, Lymphocyte $\left(\times 10^{8} / \mathrm{L}\right)$, Granules $(\times$ 108/L), Monocyte( $\left.\times 10^{8} / L\right)$.

\section{Serum Biochemical Profile}

After $12 \mathrm{~h}$ fasting, blood samples from 8 birds were collected in non-anticoagulant tubes at 42 days of 
age in each treatment group from the wing vein. The blood was stored at $4{ }^{\circ} \mathrm{C}$ for $12 \mathrm{~h}$ and then serum was collected. Individual serum samples were analyzed automatically (Mindray, BS-200, China) including total protein(TP, g/L), albumin(g/L), glucose(mmol/L), total cholesterol(TC, $\mathrm{mmol} / \mathrm{L})$, high-density lipoprotein cholesterol (HDL-C, mmol/L), low-density lipoprotein cholesterol ( $\mathrm{LDL}-\mathrm{C}, \mathrm{mmol} / \mathrm{L})$, triglyceride ( $\mathrm{TG}, \mathrm{mmol} / \mathrm{L}$ ), aspartate aminotransferase (AST, U/L), alanine aminotransferase (ALT, U/L), $\gamma$-glutamyl-transferase $(\gamma$ $\mathrm{GT}, \mathrm{U} / \mathrm{L}$ ), total bilirubin (T-bil, $\mu \mathrm{mol} / \mathrm{L}$ ), direct bilirubin(Dbil, $\mu \mathrm{mol} / \mathrm{L})$, uric acid (UA, $\mu \mathrm{mol} / \mathrm{L})$, creatinine ( $\mu \mathrm{mol} / \mathrm{L})$, urea $(\mu \mathrm{mol} / \mathrm{L})$, creatine kinase $(C K, U / L)$, lactic dehydrogenase ( $\mathrm{LDH}, \mathrm{U} / \mathrm{L})$, calcium, magnesium and inorganic phosphorus.

\section{Statistical Analysis}

The obtained results were expressed as mean \pm SD (standard deviation). Data were analyzed with PASW (PASW Statistics, Version 18.0) that the values obtained were subjected to an ANOVA, followed by Tukey's posthoc test to compare the means. For performance traits, each pen was considered as the experimental unit. Meanwhile, each bird acts as the experimental unit for the other traits. Differences in mortality between groups were analyzed using a chi-square test. Values of $p<0.05$ were considered significant.

Table 1 - Composition and nutrient levels of basal diet (air-dry basis) \%.

\begin{tabular}{lcc}
\hline Item & $0-21 \mathrm{~d}$ & $22-42 \mathrm{~d}$ \\
\hline Ingredients & & \\
Corn & 62.0 & 64.0 \\
Soybean meal & 29.1 & 27.8 \\
Soybean oil & 3.0 & 3.0 \\
Fish powder & 3.0 & 2.5 \\
Calcium hydrogen phosphate & 1.6 & 1.4 \\
Sodium chloride & 0.30 & 0.30 \\
Premix $^{1}$ & 1.0 & 1.0
\end{tabular}

\begin{tabular}{lcc} 
Nutrient level & & \\
\hline ME/(MJ/kg) ${ }^{2}$ & 12.96 & 13.03 \\
Crude protein & 20.50 & 20.02 \\
Lysine & 1.05 & 1.02 \\
Methionine+Cystine & 0.80 & 0.78 \\
Calcium & 1.01 & 1.00 \\
\hline Total phosphorus & 0.71 & 0.67 \\
\hline
\end{tabular}

${ }^{1}$ The premix provided the following nutrients per kilogram of diets: vitamin A 7000 IU, vitamin D3 $875 \mathrm{IU}$, vitamin E $20 \mathrm{IU}$, vitamin K3 $1 \mathrm{mg}$, vitamin B1 2 mg, vitamin B2 $4.5 \mathrm{mg}$, D-pantothenic acid $12 \mathrm{mg}$, nicotinic acid $50 \mathrm{mg}$, vitamin B6 $2.5 \mathrm{mg}$, vitamin B12 0.6 mg, Mn (as manganese sulfate) 66 mg, Zn 44 mg, Cu (as copper sulfate) $9 \mathrm{mg}$, Fe (as ferrous sulfate) $50 \mathrm{mg}$, I (as potassium iodide) $0.4 \mathrm{mg},{ }^{2} \mathrm{ME}$ was a calculated value.

\section{RESULTS}

\section{Growth Performance}

There were no significant differences in the initial body weight between all the experimental groups. The HS group had lower $(p<0.05)$ final body weight, average daily gain, feed intake and EBI but higher FCR than those of the control group (Table 2). However, the addition of different levels of FA groups made a higher final body weight, average daily gain and $\mathrm{EBI}$ but a lower FCR in comparison with the HS group. FA did not affect cumulative feed consumption when compared with the HS group. The mortality rate was measured to be higher in the HS treatments $(11.11 \%$ for the HS group compared to $2.87 \%$ for the control birds), although the differences did not reach statistical significance. Broiler chickens in the HS group had a significant $(p<0.05)$ higher mortality rate when compared with $1.0 \%$ and $1.5 \%$ FA supplemented groups.

\section{Hematological Parameters}

Variations of hematological parameters in heatstressed broiler chickens were presented in Table 3. The $\mathrm{Hb}$ concentration and PCV of broiler chickens under chronic HS were significantly lower than those of the control birds. Birds administered 0.5\% FA had significantly $(p<0.05)$ higher RBC and $\mathrm{Hb}$ concentration compared with birds in the HS group. There were no significant variations such as $\mathrm{MCV}, \mathrm{MCH}, \mathrm{WBC}$, lymphocytes, granules and monocytes among all experimental groups.

\section{Serum Biochemistry Parameters}

Data presented in Table 4 showed that, compared with the control group, the HS group exhibited a significant increase in glucose, TG, TC and LDL-C. However, the concentrations of TP, albumin, globulin and HDL-C in the serum did not show significant changes. Dietary $0.5 \%$ FA supplementation group had an increase in serum TP, albumin, globulin, TC, HDL-C but a decrease in TG concentration in comparison with the HS group. A significant reduction in serum glucose, TC and LDL-C were observed in dietary 1.5\% FA supplementation compared with the HS group. There were no significant differences in the concentrations of TG and glucose among dietary FA supplemented groups.

Results of serum parameters of liver, kidney and heart represented in Table 5 revealed that HS decreased ALT activity and urea content but increase creatinine 
Table 2 - Effects of FA on growth performance in heat-stressed broilers $(n=4)$.

\begin{tabular}{lccccc}
\hline Item & Control & $H S$ & $H S+0.5 \%$ FA & $H S+1 \%$ FA & $H S+1.5 \%$ FA \\
\hline Initial body weight(kg) & $0.67 \pm 0.10$ & $0.65 \pm 0.09$ & $0.66 \pm 0.11$ & $0.66 \pm 0.12$ & $0.65 \pm 0.11$ \\
Final body weight(kg) & $2.42 \pm 0.14^{\mathrm{a}}$ & $1.94 \pm 0.11^{\mathrm{c}}$ & $2.10 \pm 0.16^{\mathrm{b}}$ & $2.11 \pm 0.14^{\mathrm{b}}$ & $2.25 \pm 0.19^{\mathrm{b}}$ \\
Average daily gain(g/d) & $83.33 \pm 5.71^{\mathrm{a}}$ & $61.43 \pm 6.07^{\mathrm{d}}$ & $68.57 \pm 4.77^{\mathrm{c}}$ & $69.05 \pm 7.63^{\mathrm{c}}$ & $76.20 \pm 6.13^{\mathrm{b}}$ \\
Feed intake(g/d) & $160.71 \pm 11.90^{\mathrm{a}}$ & $142.38 \pm 10.00^{\mathrm{b}}$ & $143.42 \pm 11.43^{\mathrm{b}}$ & $138.71 \pm 15.71^{\mathrm{b}}$ & $148.58 \pm 10.47^{\mathrm{b}}$ \\
FCR & $1.93 \pm 0.02^{\mathrm{c}}$ & $2.32 \pm 0.11^{\mathrm{a}}$ & $2.09 \pm 0.06^{\mathrm{b}}$ & $2.00 \pm 0.05^{\mathrm{bc}}$ & $1.95 \pm 0.10^{\mathrm{c}}$ \\
EBI & $402.10 \pm 17.89^{\mathrm{a}}$ & $235.37 \pm 20.38^{\mathrm{d}}$ & $305.24 \pm 10.49^{\mathrm{c}}$ & $345.25 \pm 18.23^{\mathrm{b}}$ & $390.77 \pm 16.52^{\mathrm{a}}$ \\
\hline
\end{tabular}

Means within a row with different superscripts indicate significant difference $(p<0.05)$. HS: Heat stress; FA: Fumaric acid; FCR: Feed conversion ratio; EBI: European broiler indexes.

Table 3 - Effects of FA on hematological responses in heat-stressed broiler chickens ( $n=8)$.

\begin{tabular}{lccccc}
\hline Parameters & Control & $H S$ & $H S+0.5 \% F A$ & $H S+1 \% F A$ & $H S+1.5 \% F A$ \\
\hline$R B C\left(\times 10^{12} / \mathrm{L}\right)$ & $2.28 \pm 0.37^{\mathrm{ab}}$ & $2.17 \pm 0.22^{\mathrm{b}}$ & $2.38 \pm 0.24^{\mathrm{a}}$ & $2.30 \pm 0.34^{\mathrm{ab}}$ & $2.18 \pm 0.21^{\mathrm{b}}$ \\
\hline $\mathrm{Hb}$ concentration $(\mathrm{g} / \mathrm{L})$ & $99.33 \pm 11.15^{\mathrm{a}}$ & $94.29 \pm 9.46^{\mathrm{b}}$ & $100.83 \pm 6.91^{\mathrm{a}}$ & $95.14 \pm 15.26^{\mathrm{b}}$ & $94.57 \pm 11.15^{\mathrm{b}}$ \\
$\mathrm{PCV}(\%)$ & $33.78 \pm 2.84^{\mathrm{a}}$ & $29.33 \pm 3.20^{\mathrm{b}}$ & $31.92 \pm 2.62^{\mathrm{ab}}$ & $30.64 \pm 3.99^{\mathrm{ab}}$ & $29.7 \pm 3.29^{\mathrm{ab}}$ \\
$\mathrm{MCV}(\mathrm{fL})$ & $138.09 \pm 3.11$ & $135.88 \pm 6.32$ & $139.2 \pm 4.31$ & $139.49 \pm 5.51$ & $136.26 \pm 3.72$ \\
$\mathrm{MCH}(\mathrm{pg})$ & $44.00 \pm 1.28$ & $43.43 \pm 3.07$ & $44.01 \pm 1.69$ & $43.29 \pm 2.58$ & $43.27 \pm 1.74$ \\
$\mathrm{MCHC}(\mathrm{g} / \mathrm{L})$ & $319.13 \pm 6.17^{\mathrm{a}}$ & $321.29 \pm 7.76^{\mathrm{a}}$ & $316.5 \pm 5.61^{\mathrm{ab}}$ & $310.71 \pm 8.44^{\mathrm{b}}$ & $317.86 \pm 6.91^{\mathrm{a}}$ \\
\hline WBC $\left(\times 10^{8} / \mathrm{L}\right)$ & $221.8 \pm 14.36$ & $220.44 \pm 13.48$ & $221.19 \pm 19.51$ & $215.49 \pm 19.35$ & $220.07 \pm 13.37$ \\
Lymphocyte $\left(\times 10^{8} / \mathrm{L}\right)$ & $151.71 \pm 6.16$ & $152.33 \pm 6.86$ & $152.93 \pm 8.62$ & $150.3 \pm 8.59$ & $151.86 \pm 5.23$ \\
Granules $\left(\times 10^{8} / \mathrm{L}\right)$ & $50.86 \pm 10.01$ & $48.39 \pm 6.58$ & $49.34 \pm 9.91$ & $46.06 \pm 9.61$ & $48.67 \pm 7.43$ \\
Monocytes $\left(\times 10^{8} / \mathrm{L}\right)$ & $19.56 \pm 2.28$ & $19.73 \pm 0.83$ & $18.93 \pm 2.05$ & $19.13 \pm 2.43$ & $19.54 \pm 1.37$ \\
\hline
\end{tabular}

Means within a row with different superscripts indicate significant difference $(p<0.05)$. HS: Heat stress; FA: Fumaric acid; RBC: Total erythrocyte count; Hb: Hemoglobin concentration; PCV: Packed cell volume; MCV: Mean corpuscular volume; MCH: Mean corpuscular hemoglobin; MCHC: Mean corpuscular hemoglobin concentration; WBC: Total leucocyte count.

Table 4 - Effect of FA on serum protein, glucose and lipids in heat-stressed broilers $(n=8)$.

\begin{tabular}{lccccc}
\hline Parameters & Control & HS & $H S+0.5 \% F A$ & $H S+1 \% F A$ & $H S+1.5 \% F A$ \\
\hline TP(g/L) & $27.81 \pm 4.28^{\mathrm{b}}$ & $29.70 \pm 3.45^{\mathrm{b}}$ & $34.35 \pm 4.40^{\mathrm{a}}$ & $31.90 \pm 4.13^{\mathrm{ab}}$ & $29.33 \pm 3.22^{\mathrm{b}}$ \\
Albumin(g/L) & $9.16 \pm 1.57^{\mathrm{b}}$ & $9.07 \pm 1.13^{\mathrm{b}}$ & $11.28 \pm 1.94^{\mathrm{a}}$ & $10.25 \pm 1.30^{\mathrm{ab}}$ & $8.48 \pm 0.69^{\mathrm{b}}$ \\
Globulin(g/L) & $18.65 \pm 2.78^{\mathrm{b}}$ & $20.35 \pm 3.10^{\mathrm{b}}$ & $23.34 \pm 3.82^{\mathrm{a}}$ & $21.95 \pm 5.17^{\mathrm{ab}}$ & $20.73 \pm 2.90^{\mathrm{b}}$ \\
\hline Glucose(mmol/L) & $12.81 \pm 1.07^{\mathrm{c}}$ & $15.53 \pm 2.14^{\mathrm{a}}$ & $14.56 \pm 0.49^{\mathrm{ab}}$ & $14.93 \pm 1.14^{\mathrm{ab}}$ & $13.03 \pm 1.41^{\mathrm{bc}}$ \\
\hline $\mathrm{TG}(\mathrm{mmol} / \mathrm{L})$ & $0.86 \pm 0.12^{\mathrm{b}}$ & $1.03 \pm 0.07^{\mathrm{a}}$ & $0.74 \pm 0.21^{\mathrm{b}}$ & $0.84 \pm 0.13^{\mathrm{b}}$ & $0.96 \pm 0.17^{\mathrm{ab}}$ \\
$\mathrm{TC}(\mathrm{mmol} / \mathrm{L})$ & $3.16 \pm 0.15^{\mathrm{c}}$ & $3.61 \pm 0.54^{\mathrm{b}}$ & $4.64 \pm 0.54^{\mathrm{a}}$ & $4.31 \pm 0.6^{\mathrm{ab}}$ & $3.17 \pm 0.43^{\mathrm{c}}$ \\
$\mathrm{HDL}-\mathrm{C}(\mathrm{mmol} / \mathrm{L})$ & $2.18 \pm 0.26^{\mathrm{c}}$ & $2.30 \pm 0.37^{\mathrm{bc}}$ & $3.00 \pm 0.35^{\mathrm{a}}$ & $2.41 \pm 0.33^{\mathrm{b}}$ & $2.23 \pm 0.37^{\mathrm{bc}}$ \\
LDL-C(mmol/L) & $0.52 \pm 0.08^{\mathrm{c}}$ & $0.95 \pm 0.48^{\mathrm{b}}$ & $1.1 \pm 0.19^{\mathrm{ab}}$ & $1.31 \pm 0.37^{\mathrm{a}}$ & $0.65 \pm 0.21^{\mathrm{c}}$ \\
\hline
\end{tabular}

Means within a row with different letters differ significantly at $p<0.05$. HS: Heat stress; FA, Fumaric acid; TP: Total protein; TG: Triglyceride; TC: Total cholesterol; HDL-C: High-density lipoprotein cholesterol; LDL-C: Low-density lipoprotein cholesterol.

compared with the control group. Dietary 0.5\% FA supplemented increased AST activity but decreased creatinine levels in comparison with the HS group. Dietary $1.5 \%$ FA increased ALT activity but decreased serum creatinine content compared with the HS group. There were no significant changes in CK and $\gamma$-GT activities and serum T-bil, D-bil, UA between all treatment groups including the control group.

Serum contents of calcium, magnesium and inorganic phosphorus are shown in Table 6. There were no significant changes in contents both calcium and magnesium among all experimental groups. When compared with the control group, serum levels of phosphorus had a significant decrease in the HS group. However, dietary 1.5\% FA addition increased the phosphorus concentration in comparison with the the HS group.

\section{DISCUSSION}

In this study, HS decreased final body weight and body weight gain of broilers, which was probably due to decreased feed intake and feed efficiency, as demonstrated by Sohail et al. (2012). Salles et al. (2010) reported that the uptake of nutrients in heat-stressed animals diminishes due to a decrease in the ability of the intestinal to absorb nutrients. These results demonstrated that broiler chickens have ineffective thermoregulation ability under high temperature conditions and are highly susceptible to HS. Broilers fed the diets supplemented with FA showed a significant improvement in the body weight gain and FCR compared with the HS group due to better utilization of nutrients. However, there is no difference in the cumulative feed consumption 
Table 5 - Effect of FA supplementation on serum parameters of liver, kidney and cardiac functions in heat-stressed broilers $(n=8)$.

\begin{tabular}{|c|c|c|c|c|c|}
\hline Parameters & Control & $\mathrm{HS}$ & $\mathrm{HS}+0.5 \% \mathrm{FA}$ & $\mathrm{HS}+1 \% \mathrm{FA}$ & $\mathrm{HS}+1.5 \% \mathrm{FA}$ \\
\hline AST(U/L) & $279.95 \pm 42.51^{b}$ & $289.67 \pm 59.52^{b}$ & $372.34 \pm 43.98^{a}$ & $327.39 \pm 76.43^{\mathrm{ab}}$ & $263.75 \pm 31.78^{b}$ \\
\hline $\operatorname{ALT}(\mathrm{U} / \mathrm{L})$ & $7.97 \pm 2.05^{a}$ & $3.68 \pm 0.46^{c}$ & $4.26 \pm 0.81^{b c}$ & $3.97 \pm 0.88^{b c}$ & $4.64 \pm 1.05^{b}$ \\
\hline$\gamma-\mathrm{GT}(\mathrm{U} / \mathrm{L})$ & $18.12 \pm 2.63$ & $18.75 \pm 5.58$ & $18.75 \pm 3.24$ & $20.32 \pm 5.47$ & $16.23 \pm 1.13$ \\
\hline T-bil $(\mu \mathrm{moL} \cdot / \mathrm{L})$ & $2.42 \pm 0.54$ & $2.76 \pm 0.75$ & $2.11 \pm 0.5$ & $2.56 \pm 0.75$ & $2.06 \pm 0.25$ \\
\hline D-bil( $\mu \mathrm{moL} \cdot / \mathrm{L})$ & $2.19 \pm 0.47$ & $2.32 \pm 0.37$ & $1.89 \pm 0.27$ & $2.32 \pm 0.76$ & $2 \pm 0.32$ \\
\hline $\mathrm{UA}(\mu \mathrm{moL} \cdot / \mathrm{L})$ & $199.76 \pm 21.29$ & $202.43 \pm 29.62$ & $171.5 \pm 32.58$ & $186.2 \pm 49.97$ & $210.12 \pm 34.47$ \\
\hline Creatinine $(\mu \mathrm{moL} \cdot / \mathrm{L})$ & $6.10 \pm 0.92^{b c}$ & $8.08 \pm 1.67^{a}$ & $6.72 \pm 0.31^{b}$ & $7.12 \pm 2.14^{\mathrm{ab}}$ & $5.20 \pm 0.68^{c}$ \\
\hline Urea( $\mu \mathrm{moL} \cdot / \mathrm{L})$ & $0.71 \pm 0.20^{\mathrm{a}}$ & $0.53 \pm 0.12^{b}$ & $0.63 \pm 0.16^{\mathrm{ab}}$ & $0.55 \pm 0.15^{b}$ & $0.56 \pm 0.11^{\mathrm{ab}}$ \\
\hline $\mathrm{CK}(\mathrm{U} / \mathrm{L})$ & $5163.68 \pm 951.09$ & $5215.05 \pm 999.23$ & $4839.08 \pm 877.22$ & $4934.38 \pm 817.33$ & $5330.74 \pm 656.20$ \\
\hline $\mathrm{LDH}(\mathrm{U} / \mathrm{L})$ & $1159.78 \pm 511.83^{b}$ & $1232.58 \pm 305.73^{a b}$ & $1624.77 \pm 345.46^{a}$ & $1553.47 \pm 356.8^{a}$ & $1162.46 \pm 264.97^{b}$ \\
\hline
\end{tabular}

Means within a row with different letters differ significantly at $p<0.05$. HS: Heat stress; FA: Fumaric acid; AST: Aspartate aminotransferase; ALT: Alanine aminotransferase; $\gamma$-GT: $\gamma$-glutamyl-transferase; T-bil: Total bilirubin; D-bil: Direct bilirubin; UA: Uric acid; CK: Creatine kinase; LDH: Lactic dehydrogenase.

Table 6 - Effect of FA supplementation on serum contents of calcium, magnesium and phosphorus in heat-stressed broilers $(n=8)$.

\begin{tabular}{lccccc}
\hline Parameters & Control & $H S$ & $H S+0.5 \% F A$ & $H S+1 \% F A$ & $H S+1.5 \% F A$ \\
\hline Calcium(mmol/L) & $2.48 \pm 0.10$ & $2.42 \pm 0.20$ & $2.51 \pm 0.27$ & $2.53 \pm 0.17$ & $2.46 \pm 0.12$ \\
Magnesium(mmol/L) & $0.99 \pm 0.14$ & $0.92 \pm 0.08$ & $1.00 \pm 0.13$ & $0.93 \pm 0.10$ & $0.89 \pm 0.09$ \\
Inorganic phosphorus (mmol/L) & $2.3 \pm 0.27^{\mathrm{a}}$ & $1.95 \pm 0.85^{\mathrm{b}}$ & $1.95 \pm 0.17^{\mathrm{b}}$ & $1.99 \pm 0.21^{\mathrm{b}}$ & $2.26 \pm 0.18^{\mathrm{a}}$ \\
\hline
\end{tabular}

Means within a row with different letters differ significantly at $p<0.05$. HS: Heat stress; FA, Fumaric acid.

between HS and the groups fed FA. That is to say, FA supplementation alleviates the negative effects of HS on growth performance, as reflected by an increasing body weight gain which by improving FCR rather than feed intake. These results are in accordance with some previous studies where broilers were reared under normal ambient temperature conditions (Islam et al., 2008). The improvement of body weight gain is probably due to the beneficial bactericidal effect of FA and the improved energy metabolism (Ricke 2003). Also, such a positive impact of dietary FA on growth performance might be related to the intestinal protection effect of FA which improves the $\mathrm{pH}$ values in the feed and digestive tract (Kamal et al., 2014; Liu et al., 2008). Kim et al. (2015) also reported that dietary ingredients and their chemical properties and microbial load in the environment could be the main factors for practical application results. The results of the present study regarding mortality rate and EBI agree with Marin-Flamand et al. (2014) who reported that organic acids could reduce the production of toxic components by the bacteria and colonization of pathogens on the intestinal wall which improve the survival rate and feeding efficiency.

Broiler chickens, bred for high performance, have been shown to have increased susceptibility to environmental stresses than ever before. Based on the present study, heat-stressed broilers have a numerical decrease in $\mathrm{RBC}$ and a significant decrease in $\mathrm{Hb}$ and
PCV compared with the control broilers. Lower levels of $\mathrm{Hb}$ in the chicken blood may be related to the effect of HS on changes in the distribution of iron in the organism and thus the decreased RBC and PCV (Jamadar et al., 1995). Moreover, it has been showed that HS-induced oxidative damage to hemoglobin molecules can cause denaturation and hydrophobicity of $\mathrm{Hb}$ molecules, which signal a rapid intracellular selective degradation of the damaged hemoglobin molecules by the proteolytic system (Giulivi et al., 1994).Also, several studies have reported a decrease in $\mathrm{RBC}, \mathrm{PCV}$, and $\mathrm{Hb}$ values during HS, which is believed to be caused by excess water intake (Mazzullo et al., 2014). Our results are different from those of Habibu et al. (2018) who reported that an increase in RBC, $\mathrm{Hb}$ and PCV occurs during dehydration or splenic contraction induced by $\mathrm{HS}$. Since $\mathrm{MCH}$ and $\mathrm{MCHC}$ are calculated using $\mathrm{Hb}, \mathrm{PCV}$ and/or RBC, any change in $\mathrm{Hb}, \mathrm{PCV}$ and $\mathrm{RBC}$ is directly reflected in $\mathrm{MCH}$ and MCHC. The findings of the present study showed that broiler chickens administered 0.5\% FA had significantly higher $\mathrm{RBC}$ and $\mathrm{Hb}$. This finding implies that the administration of FA enhanced the oxygencarrying capacity and consequently, more nutrients are available under the thermally stressful environmental conditions (Oleforuh-Okoleh et al., 2015).

The leucocyte parameters are mainly influenced by the effects of neuroendocrine products from the hypothalamic-pituitary-adrenal axis. The results of the 
present study demonstrated that broiler chickens in different groups had no significant difference in WBC, lymphocytes, granules and monocytes. This finding may suggest that the birds employed thermoregulatory mechanisms to cope with the thermally stressful environmental conditions. However, Habibu et al. (2016) reported that HS decrease lymphocytes implicating the immunosuppressive effect of HS during the hot season. Hence, depending on animal species, duration of heat exposure and capacity of the animal heat adaptation, different reports may vary in their leucocytic response to HS.

When birds are subjected to HS, they use various strategies such as physiological and biochemical adjustments to maintain homeostasis. HS did not change serum TP, albumin and globulin compared with the control group. However, Dietary $0.5 \%$ FA supplementation group had an increase in serum TP, albumin and globulin. The significant increase in total protein could be due to the achieved significant increase in the serum concentration of albumin and globulin by the supplemented groups. These results indicated that supplemental FA might improve the protein synthesis in broiler liver. Also, broiler chickens fed FA had the better immune response as indicated by a higher serum globulin level than the control group. This result is in harmony with those of Kamal et al. (2014) and Rahmani et al. (2005) who found higher globulin in broilers given organic acids than the control group. The enhancement of immune response associated with dietary FA could be due to their inhibitory effects against the pathogenic microorganisms throughout the gastrointestinal tract (Kim et al., 2015).

There was a significant increase in the concentrations of glucose in HS group which in agreement with Chand et al. (2018) who reported that serum glucose concentration may increase with chronic HS. The increased blood glucose could be due to the endocrine activity of adrenal hormones, which accelerate gluconeogenesis and indicates the alteration of chicken energetic metabolism (Lu et al., 2018). This result is contrary to the findings of Sands et al. (1999) who reported that plasma glucose concentration of broilers decreases under HS. This inconsistent result may be related to the broiler species, exposure duration and intensity. However, a significant decrease in serum glucose was observed in dietary 1.5\% FA supplementation compared with HS group which indicated that FA has a positive effect on energetic metabolism in heat-stressed broilers.

Superficially, the observed lower feed consumption and consequently, lower fat intake would result in fat depletion and may contribute to reducing blood lipid content. However, it is known that HS can lead to an increased abnormal fat deposition by increasing, total cholesterol and LDL-C levels, which were confirmed by the present study. Our findings are in agreement with the results of Fallah (2013), who reported that serum cholesterol in broiler was higher under high ambient temperature. These results showed that lipid metabolism has a special adaption mechanism in heatstressed broilers. There was a numerical decrease in cholesterol and reduced triglyceride levels in the FAtreated groups compared to the HS group. The findings of serum lipid profile are in agreement with Dousa et al. (2016), who reported that blood total lipids and cholesterol decreased significantly by dietary acidifiers.

HS decreased the ALT activity and urea but increased the creatinine, which shows that, in part, HS have adverse effects on the liver and renal function after 21 days of heat exposure. The result shows that HS decreased the ALT activity indicating HS decreased the metabolic rate of liver cells. Our findings are different from the results of Chand et al. (2018), who reported increased AST and serum ALT level for broilers exposed to high temperature. Dietary 0.5\% FA made a temporary increase in comparison with HS and the reason should be further explored. The decreased serum urea in HS group demonstrated that protein metabolism changed and broilers may have a low protein metabolic rate. The increased creatinine may suggest that chronic HS has a negative impact on renal function. However, our result shows that the FA has an alleviated role in heat-stressed broilers. In addition, the increased LDH activity may be related to the regulation of glycolysis and citric acid cycle in broilers under high ambient temperature condition.

Improvement of the utilization of calcium and phosphorus by organic acids supplementation was revealed by Moghadam et al. (2006) who reported that the acidic anion shows to be complex with calcium, phosphorus, magnesium and zinc, which results in an improved digestibility of these minerals. Compared with HS group, the numerical increase of calcium, magnesium and phosphorus levels in blood serum produced by the addition of FA may be attributed to the lowering of gastrointestinal tract $\mathrm{pH}$, which increases the absorption of such minerals from the gut into the bloodstream.

\section{CONCLUSIONS}

It has been shown that dietary FA had positive effects on final body weight, average daily gain and 
$\mathrm{EBI}$ in broiler chickens under HS conditions. Also, birds administered FA had significantly higher erythrocyte counts, hemoglobin concentration, and the serum total protein, albumin, globulin, total cholesterol, high-density lipoprotein cholesterol in comparison with the HS group. These results demonstrated that the improved growth performance may be related to the improved hematological parameters and serum biochemical states in the heat-stressed broilers.

\section{ACKNOWLEDGMENTS}

This study was supported by grants from the National Natural Science Foundation of China (Grant No. 31601983, 31702306), Natural Science Foundation of Anhui Province (Grant No.1908085QC 145) and Natural Science Foundation of Anhui Provincial Department of Education (No. KJ2018ZD052).

\section{REFERENCES}

Adil S. A study on efficacy of fumaric acid supplementation in diet of broiler chicken. International Journal Poultry Science 2015;14(11):589-594.

Chand N, Naz S, Rehman Z, Khan RU. Blood biochemical profile of four fast-growing broiler strains under high ambient temperature. Applied Biological Chemistry 2018;61(3):273- 279

Collier RJ, Renquist BJ, Xiao Y. A 100-year review: stress physiology including heat stress. Journal Dairy Science 2017;100(1 2):10367-10380.

Dousa BM, Adam MS, Malik H, Ali O, Elamin K, Elagib AA. Impact of probiotics and acidifiers on growth performance and blood chemistry of broiler chickens. International Journal Science and Research 2016;5(10):1670-1675.

Durek J, Ghadiri Khozroughi A, Fröhling A, Schlüter O, Knorr F, Mader A, et al. Effects of thermally treated broiler feed with different organic acid levels on resulting meat composition and parameters related to meat quality. Innovative Food Science and Emerging Technologies 2014;26:397-405.

EFSA. Panel on additives and products or substances used in animal feed, scientific opinion on the safety and efficacy of AviMatrix $®$ (benzoic acid, calcium formate and fumaric acid) for chickens for fattening, chickens reared for laying, minor avian species for fattening and minor avian species reared to point of lay. EFSA Journal 2016;13(5):3794.

Fallah R. Effect of dietary prebiotic and acidifier supplementation on the growth performance, carcass characteristics and serum biochemical parameters of broilers. Journal Cell Animal Biology 2013;7(3):21- 24

Giulivi C, Pacifici RE, Davies KJA. Exposure of hydrophobic moieties promotes the selective degradation of hydrogen peroxide-modified hemoglobin by the multicatalytic proteinase complex, proteasome. Archives Biochemistry and Biophysics 1994;311(2):329-341.

Habibu B, Dzenda T, Ayo JO, Yaqub LS, Kawu MU. Haematological changes and plasma fluid dynamics in livestock during thermal stress, and response to mitigative measures. Livestock Science 2018;214(8):189201.

Habibu B, Kawu MU, Aluwong T, Makun HJ. Influence of seasonal changes on physiological variables, haematology and serum thyroid hormones profile in male Red Sokoto and Sahel goats. Journal Applied Animal Research 2016;45:1-9

He X, Lu Z, Ma B, Zhang L, Li J, Jiang Y, et al. Effects of chronic heat exposure on growth performance, intestinal epithelial histology, appetite-related hormones and genes expression in broilers. Journal Science Food and Agriculture 2018;98(12):4471-4478.

Islam KMS, Schuhmacher A, Aupperle H, Gropp JM. Fumaric acid in broiler nutrition:A dose titration study and safety aspects. International Journal Poultry Science 2008;7(9):903-907.

Islam KMS, Schaeublin H, Wenk C, Wanner M, Liesegang A. Effect of dietary citric acid on the performance and mineral metabolism of broiler[J]. Journal Animal Physiology and Animal Nutrition 2012;96(5):808-817.

Jamadar SJ, Jalnapurkar BV. Effect of high ambient temperature on iron status of broilers. Indian Veterinary Journal1995;72(6):577-579.

Kamal AM, Ragaa NM. Effect of dietary supplementation of organic acids on performance and serum biochemistry of broiler chicken. Nature and Science 2014;12(2):38-45.

Kim JW, Kim JH, Kil DY. Dietary organic acids for broiler chickens: a review. Revista Colombiana de Ciencias Pecuarias 2015;28(2):109-123.

Lara L, Rostagno M. Impact of heat stress on poultry production. Animals 2013:3(2):356-369

Liu Y, Yang $X$, Xin H, Chen S, Yang C, Duan Y, et al. Effects of a protected inclusion of organic acids and essential oils as antibiotic growth promoter alternative on growth performance, intestinal morphology and gut microflora in broilers. Animal Science Journal 2017;88(9):14141424

Lu Z, He X, Ma B, Zhang L, Li J, Jiang Y, et al. Serum metabolomics study of nutrient metabolic variations in chronic heat-stressed broilers. British Journal of Nutrition 2018;119(7):771-781.

Marin-Flamand E, Vazquez-Duran A, Mendez-Albores A. Effect of organic acid blends in drinking water on growth performance, blood constituents and immune response of broiler chickens. Journal Poultry Science 2014;51(2):144-150.

Mazzullo G, Rifici C, Caccamo G, Rizzo M, Piccione G. Effect of different environmental conditions on some haematological parameters in cow. Annals Animal Science 2014;14(4):947-954.

Moghadam AN, Pourreza J, Samie AH. Effect of different levels of citric acid on calcium and phosphorus efficiencies in broiler chicks. Pakistan Journal Biological Sciences 2006;9(7):1250-1256.

Oleforuh-Okoleh VU, Ndofor-Foleng HM, Olorunleke SO, Uguru JO. Evaluation of growth performance, haematological and serum biochemical response of broiler chickens to aqueous extract of ginger and garlic. Journal Agricultural Science 2015;7(4):167-173.

Rahmani HR, Speer W. Natural additives influence the performance and humoral immunity of broilers. International Journal Poultry Science 2005;4(9):713-717.

Ricke S. Perspectives on the use of organic acids and short chain fatty acids as antimicrobials. Poultry Science 2003;82(4):632-639.

Salles MSV, Zanetti MA, Salles FA, Titto EAL, Conti RMC. Changes in ruminal fermentation and mineral serum level in animals kept in high temperature environments. Revista Brasileira de Zootecnia 2010;39(4):883-890.

Sands JS, Smith MO. Broilers in heat stress conditions: effects of dietary manganese proteinate or chromium picolinate supplementation. Journal Applied Poultry Research 1999;8(3):280-287.

Singh KM, Singh S, Ganguly I, Ganguly A, Nachiappan RK, et al. Evaluation of Indian sheep breeds of arid zone under heat stress condition. Small Ruminant Research 2016;141:113-117.

Sohail MU, Hume ME, Byrd JA, Nisbet DJ, ljaz A, Sohail A, et al. Effect of supplementation of prebiotic mannan-oligosaccharides and probiotic mixture on growth performance of broilers subjected to chronic heat stress. Poultry Science 2012;91(9):2235-2240.

Waldroup A, Kaniawati S, Mauromoustakos A. Performance characteristics and microbiological aspects of broilers fed diets supplemented with organic acids. Journal Food Protection 1995;58(5):482-489. 
